\title{
Myxoma of the Mitral Valve
}

\author{
Antônio Sérgio C. Rocha, Maria Elizabeth Ferreira, Paulo R. Dutra, Nazareth N. Rocha, Solange M. Tinoco, \\ Cesar Nascimento, Rosana Grandelle, Rita C. Villela, Marialda Coimbra, Celso Garcia
}

\author{
Rio de Janeiro, RJ - Brazil
}

\begin{abstract}
Only rarely do myxomas originate from the mitral valve. This is the report of a 49-year-old woman presenting with congestive heart failure. The diagnosis of an intracardiac tumor involving the anterior cuspid of the mitral valve was made by transesophageal echocardiography. The patient underwent surgery for tumor resection and plasty of the valve was made with reconstruction and preservation of the valve. The diagnosis of myxoma was confirmed by histology. This is the $23^{\text {rd }}$ case of myxoma of the mitral valve reported in the literature.
\end{abstract}

Most cardiac tumors are benign and the majority is myxoma ${ }^{1}$. Cardiac myxomas usually originate in the atrial septum in the area of the fossa ovalis and approximately $75 \%$ occur in the left atrium ${ }^{1,2}$. Rarely do they occur in other areas of the heart and only exceptionally are the valves involved. This is our first case of a myxoma involving the mitral valve and, as far as we know, the $23^{\text {rd }}$ case reported in the literature.

\section{Case Report}

A 49-year-old black woman was admitted to the hospital with a history of palpitations on efforts and progressive dyspnea over the previous two years. She reported no other symptoms. She had a history of systemic arterial hypertension for five years and her parents had "cardiac problems". On physical examination she had distended jugular veins at $45^{\circ}$ with increased $a$ wave in the venous jugular pulse. Both the carotid pulse and other arterial pulses were normal. On admission, her blood pressure was 160/120mmHg. Parasternal right ventricular heave was palpable in the lower left parasternal border. An apex impulse with a diameter of less than 2 fingertips was palpable and palpable valvar sounds were present at the apex and at the pulmonic area. Loud S1 and P2, as well as S4 from the $\mathrm{RV}$ could be heard. An intense protodiastolic murmur, which was interpreted as a tumor plop, could be heard in the mitral area, where a $2+/ 6+$ proto-meso systolic murmur and

Hospital de Cardiologia de Laranjeiras - Ministério da Saúde, Rio de Janeiro Mailing address: Antônio Sérgio C. Rocha - Rua Roberto Dias Lopes, 220/201 22010-110 - Rio de Janeiro, RJ - Brazil a diastolic rumble $3+/ 6+$ were also detected. Lungs were clear and there was mild hepatomegaly, which was not painful on palpation. Lower limbs showed signs of chronic venous insufficiency, with mild bilateral ankle edema.

Electrocardiogram showed left atrial enlargement and diffuse abnormalities of the ST-T segments, with flattened T waves. Moderate enlargement of the cardiac silhouette, with left atrial and right ventricular enlargement, and signs of venocapillary pulmonary hypertension were present on chest X-ray. Transthoracic echocardiogram showed a dilated left atrium and a mass could be seen attached to the anterior leaflet of the mitral valve. Transesophageal echocardiogram showed a rounded mass, with regular contours and homogenous appearance, which measured $2.5 \times 2.2 \mathrm{~cm}$ and was attached to the atrial part of the anterior leaflet of the mitral valve (fig. 1). A peak gradient of $24 \mathrm{mmHg}$ and a mean gradient of $14 \mathrm{mmHg}$ between the left atrium and ventricle were present. Coronariography showed normal coronaries and a radioluscent mass inside the left atrium projecting itself inside the left ventricle during diastole was seen by ventriculography.

The patient underwent surgery with cardiopulmonary bypass 20 days after admission. Left atriotomy showed a purple tumor which measured $2.5 \times 3.0 \mathrm{~cm}$ in its largest diameter, had regular borders and a small peduncle which was attached to the anterior leaflet of the mitral valve in its cephalic and basal portion (fig. 2). The tumor and its attachment to the mitral valve were excised and a bovine pericardium patch was used to repair the valve. Elongated cells (fusiform) and star-shaped cells in a myxomatous estroma, which are typical of myxomas, were seen by histology (fig. 3). The postoperative period was uneventful and the patient was discharged ten days after surgery. A transesophageal echocardiogram was performed before discharge, and there was mild to moderate mitral regurgitation. Fifteen months after surgery the patient was asymptomatic and there were no signs of recurrence of the tumor.

\section{Discussion}

Valvular myxomas are very rare. The tricuspid valve is the most frequently involved location, followed by the mitral, pulmonic and aortic valve ${ }^{3,4}$. In a review of the literature our patient was found to be the $23^{\text {rd }}$ reported case of 


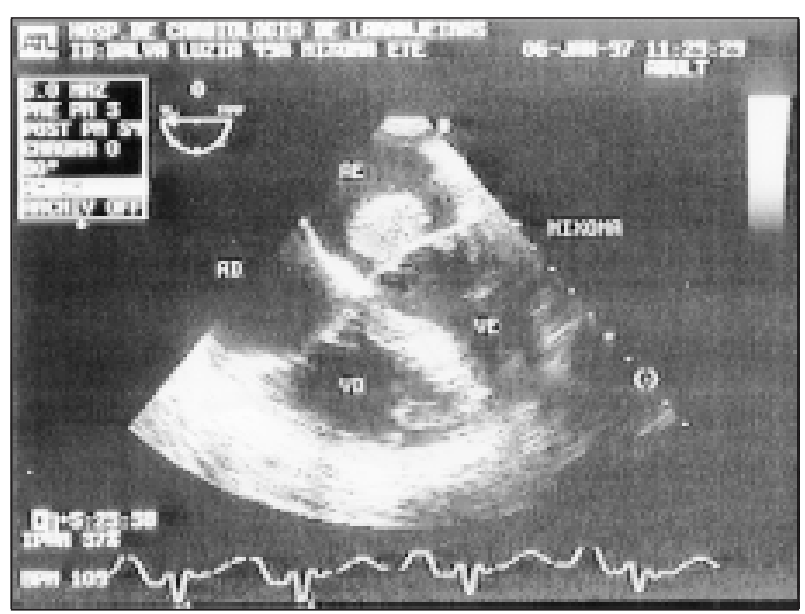

Fig. 1 - Four chamber view by transesophageal echocardiogram showing an echo mass attached to the mitral valve.

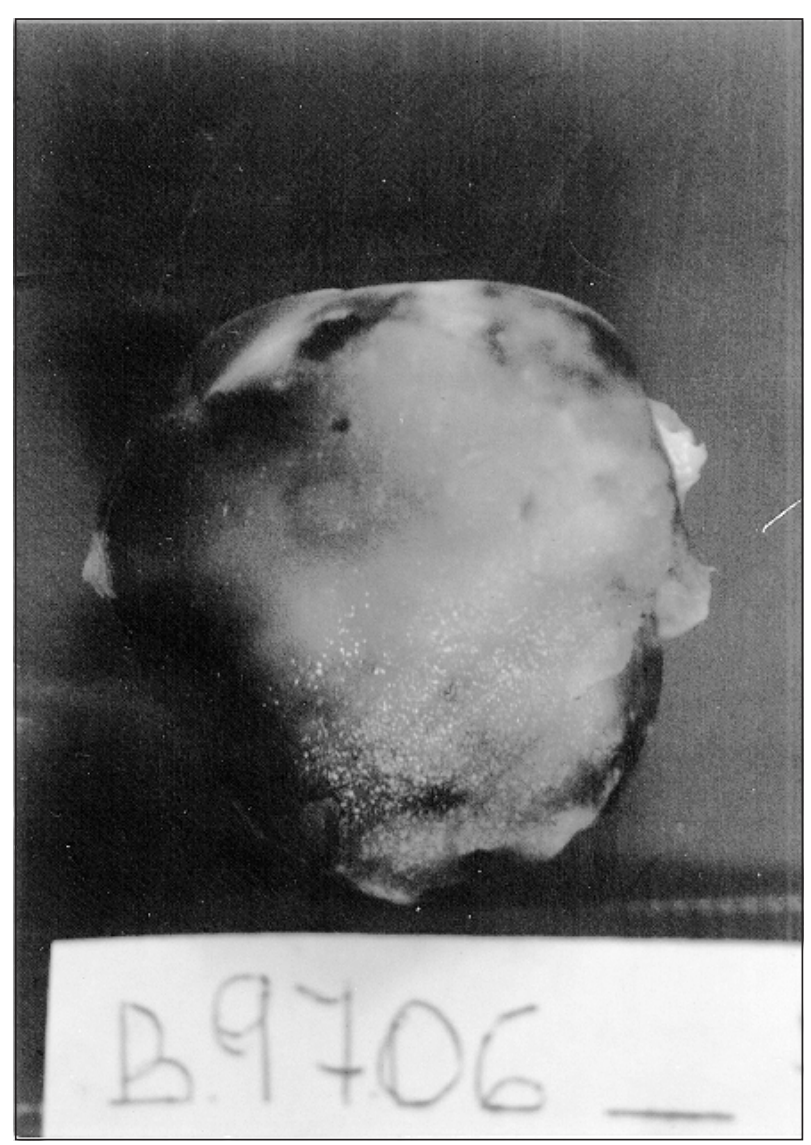

Fig. 2 - Macroscopic aspect of the tumor after surgical resection showing the rounded aspect and smooth surface of the tumor.

a myxoma in the mitral valve ${ }^{3,4}$. Myxomas are sporadic but can also be familiar ${ }^{1}$. Women are more frequently involved than men ${ }^{1,34}$, but when in the mitral valve, myxomas

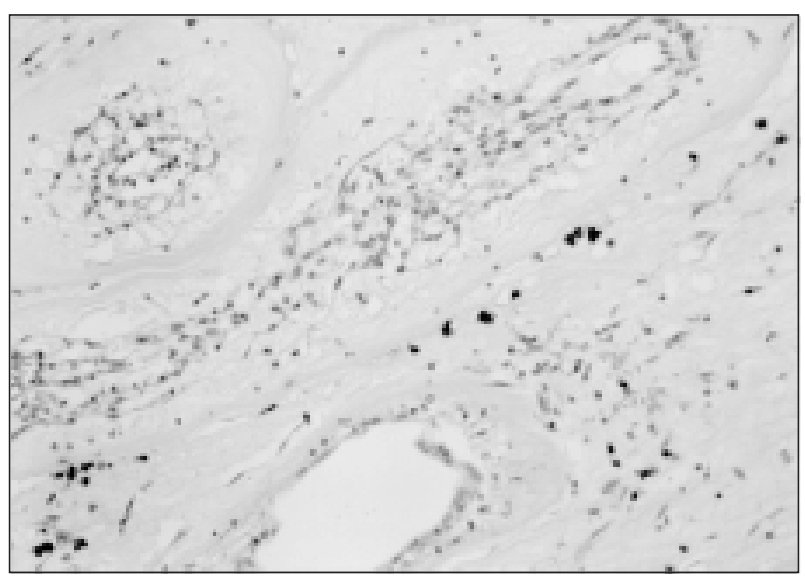

Fig. 3 - Histopathologic slide of the tumoral mass showing its long-shaped and starshaped cells, disposed in a myxomatous stroma, which is typical of myxomas.

seem to have the same occurrence in both sexes (10 men and 13 women). Sporadic cases of myxomas are usually diagnosed between the third and sixth decade of life, while mean age of the 23 patients with a mitral valve myxoma was $42 \pm 20$ years, ranging from 5 to 86 years. The most frequent clinical manifestations of the myxomas are unspecific systemic symptoms resulting from the tumoral production of interleucin-6, which occurs in $65 \%$ of the cases ${ }^{5}$. Embolic phenomena, caused by segmentation of the tumor or clot formation on its surface, occurs in $40 \%$ of the cases ${ }^{4}$ and congestive heart failure, resulting from mitral or tricuspid obstruction is seen in $65 \%$ of the cases ${ }^{5}$. The most frequently seen manifestation in myxomas of the mitral valve was cerebral or peripheral embolism (39\% of the cases). Unspecific systemic manifestations occurred in only 2 cases of mitral valve myxoma and congestive heart failure in $5(21.7 \%)$ of the 23 reported cases. When located on the mitral valve, they usually occur on the atrial surface of the valve and the anterior and posterior leaflets are involved with equal frequency ${ }^{4}$. Among the 23 reported cases (including the present one), 16 myxomas were excised by surgery and the remaining 6 were unexpectedly found by necropsy 4 (there was no information about one of the cases) ${ }^{6}$ Of the 16 patients who underwent surgery, one patient died due to tumor embolism during surgery ${ }^{4}, 12$ had their tumors excised with or without valvar repair and in three patients, tumor excision was associated with valvar replacement.

Recurrence of sporadic cases of myxoma (not familiar) is uncommon and occur in 1 to $4.7 \%$ of the cases. ${ }^{2}$ There were available date on the post-operative period of 9 of the 16 operated cases (including ours) and none showed signs of recurrence of the tumor in two to 15 months after surgery. 
Rocha et al

Arq Bras Cardiol

Myxoma of the mitral valve

volume $72,\left(n^{\circ} 5\right), 1999$

\section{References}

1. Reynen K. Cardiac Myxomas. N Engl J Med 1995; 333: 1610-17

2. Hall RA, Anderson RP. Cardiac neoplasms. In: Edmunds LH, eds. - Cardiac Surgery in the Adult. New York: McGraw-Hill, 1997: 1345.

3. Meisner JS, Daboin NP, Keller PK, Sisto DA, Factor SM, Strom JA. Myxoma of the mitral valve detected by transesophageal echocardiography. Am Heart J 1993 ; 125 : 1449-51.
4. Chakfé N, Kretz JG, Valentin P, et al. Clinical presentation and treatment options for mitral valve myxoma. Ann Thorac Surg 1997; 64: 872-7.

5. Larsson S, Lepore V, Kennergren C. Atrial myxomas: results of 25 years' esperience and review of the literature. Surgery 1985; 105: 695-8.

6. Sellke FW, Lemmer JH, Vandenberg BF, Ehrenhalft JL. Surgical treatment of cardiac myxomas: long-term results. Ann Thorac Surg 1990; 50: 557-61. 